p-ISSN 1693-9484, $e$-ISSN : 2621-8313

Majalah Ilmiah Bahari Jogja (MIBJ)

Vol. 19 No. 1, Februari 2021 (104-112)

DOI: $10.33489 /$ mibj.v19i1.261

(C) 2021 Sekolah Tinggi Maritim Yogyakarta

\title{
PENGARUH PEMBERIAN INSENTIF, PENGAWASAN KERJA \& MOTIVASI KERJA TERHADAP PRESTASI KERJA PEGAWAI PT. ARMADA BANDAR BANGUN PERSADA
}

\author{
Erita $^{1 *}$, Honest Radiansyah ${ }^{2}$, Jefry Kasdi ${ }^{3}$, Yafi Kurniawan ${ }^{4}$, \\ Aziz Surya Patih ${ }^{5}$ \\ ${ }^{1}$ Dosen Program Studi Akuntansi STKIP PGRI Sumatera Barat, Jl. Gn. Pangilun, Gn. \\ Pangilun, Kec. Padang Utara, Kota Padang, Sumatera Barat 25111 \\ ${ }^{2,3}$ Dosen Program Studi Nautika, Akademi Maritim Sapta Samudra (AMSS) Padang, \\ Lubuk Minturun, Kota Padang, Sumatera Barat, 25175 \\ ${ }^{4,5}$ Mahasiswa Program studi Nautika Akademi Maritim Sapta Samudra (AMSS) Padang, \\ Lubuk Minturun, Kota Padang, Sumatera Barat, 25175 \\ *Corresponding Author. E-mail: eritasyofyan4516@gmail.com. HP: +62 813-6344-2779
}

\begin{abstract}
Abstrak
Penelitian ini bertujuan untuk menganalisis 1) pengaruh pemberian insentif secara parsial terhadap prestasi kerja, 2) pengaruh pengawasan secara parsial terhadap prestasi kerja, 3) pengaruh motivasi kerja secara parsial terhadap prestasi kerja, 4) pengaruh pemberian insentif, pengawasan dan motivasi kerja secara stimultan terhadap prestasi kerja pegawai di Kantor PT. Armada Bandar Bangun Persada.Hasil analisis data menunjukan bahwa (1) terdapat pengaruh yang signifikan pemberian insentif terhadap prestasi kerja, nilai thitung 2,818> ttabel 1,986 ; (2) terdapat pengaruh yang signifikan antara pengawasan terhadap prestasi kerja, dengan thitung 3,269>ttabel 1,986 (3) terdapat pengaruh yang signifikan antara motivasi terhadap prestasi kerja, nilai thitung 2,332>ttabel 1,986; (4) terdapat pengaruh yang signifikan antara pemberian insentif, pengawasan dan motivasi kerja terhadap prestasi kerja dengan 16,060 > Ftabel 3,10. Besarnya pemberian insentif, pengawasan dan motivasi kerja terhadap prestasi kerja yaitu $35,1 \%$ dan sisanya $64,9 \%$ dipengaruhi oleh faktor lain yang tidak dimasukan dalam penelitian ini.
\end{abstract}

Kata Kunci : pemberian insentif, pengawasan, motivasi kerja, prestasi kerja

\begin{abstract}
This study aims to analyze 1) the effect of incentives partially on work performance, 2) effect supervision partially on work performance, 3) the effect of working motivation partially on work performance, 4) the effect of incentives, supervision and motivation, simultaneously against work performance of employees in the Office of PT.Armada Bandar Bangun Persada. The results of data analysis showed that (1) there is a significant effect of incentives on job performance, tcount 2.818> 1.986 ttabel; (2) a significant difference between the oversight of the performance, with thitung 3,269> $t$ table 1.986 (3) there is a significant relationship between motivation for work performance, tcount 2,332> 1,986 ttabel; (4) a significant difference between providing incentives, supervision and motivation on work performance with 16.060> Ftabel 3.10. The amount of
\end{abstract}


incentives, supervision and motivation on work performance is $35.1 \%$ and the remaining $64.9 \%$ is influenced by other factors not included in this study.

Keywords: incentives, supervision, motivation, work performance

\section{PENDAHULUAN}

\section{Latar Belakang}

Keberhasilan suatu organisasi sangat dipengaruhi oleh prestasi kerja pegawainya. Setiap organisasi maupun instansi pemerintahan akan selalu berusaha untuk meningkatkan prestasi kerja pegawainya, dengan harapan apa yang menjadi tujuan organisasi akan tercapai. Berbagai usaha yang dilakukan oleh organisasi dalam meningkatkan prestasi kerja pegawainya, misalnya melalui tambahan penghasilan, pengawasan dan motivasi kerja. Hal ini menuntut semua organisasi yang berhubungan dengan pelayanan hak masyarakat agar menjadi organisasi yang kompetitif yang sesuai dengan harapan kebutuhan masyarakat. Prestasi kerja dipengaruhi oleh dua hal utama yaitu, faktor organisasional (perusahaan) dan faktor personal. Faktor organisasional meliputi pemberian insentif, pengawasan, motivasi kerja, nilai dan minat.

Berdasarkan observasi yang penulis lakukan pada tanggal 5 Oktober 2015, tentang prestasi kerja pegawai di PT.Armada Bandar Bangun Persada kepada 30 orang responden.Prestasi kerja Pegawai pada PT.Armada Bandar Bangun Persada belum maksimal dicapai sesuai dengan tujuan organisasi, dari keenam pernyataan yang diajukan kepada pegawai tersebut sebanyak $44,3 \%$ pegawai menjawab ya dan sisanya menjawab tidak yaitu sebanyak 54\%. Hal ini penulis duga dipengaruhi oleh beberapa faktor-faktor salah satunya seperti pemberian insentif. Pemberian insentif kepada para pegawai diharapkan akan memberikan motivasi kepada para pegawai yang mempunyai latar belakang yang berbeda,hal ini akan memberikan dampak yang positif didalam menjalankan tugas-tugasnya agar tetap semangat dan terhindar dari menurunnya tingkat kerja pegawai yang berujung pada prestasi kerja dan kelangsungan organisasi tersebut.

Hasil observasi awal yang penulis lakukan tentang pengawasan kerja dapat terlihat bahwa pengawasan yang dilakukan di PT. Armada Bandar Bangun Persada belum maksimal karena masih adanya pegawai yang mengumpulkan laporan kerja. Dari ke empat item pernyataan yang diajukan kepada 30 orang responden sebanyak $48,35 \%$ menjawab ya dan sisanya 51,58 orang menjawab tidak. Hal ini diduga berdampak pada prestasi kerja pegawai di PT. Armada Bandar Bangun Persada.

Selain pemberian insentif dan pengawasan, prestasi kerja juga diduga dipengaruhi oleh motivasi kerja. Motivasi yang ada pada diri pegawai berdampak positif bagi organisasi, hal ini bisa dipengaruhi oleh faktor pendidikan, kepribadian maupun kebutuhannya masing-masing, dengan adanya motivasi kerja, dapat memberikan perubahan pada pegawai dalam melakukan pekerjaan,

Majalah Ilmiah Bahari Jogja 105 | http://jurnal.amy.ac.id/index.php/MIBJ/ 
sehingga tercapai tujuan pekerjaan. Apabila pegawai memiliki motivasi yang tinggi akan memberikan hasil kerja yang diinginkan.

Dari observasi awal pada tanggal 5 Oktober 2015 terlihat bahwa motivasi kerja pegawai di PT.Armada Bandar Bangun Persada masih kurang maksimal, hasil observasi data diatas menunjukan bahwa sebanyak $48,9 \%$ pegawai menjawab ya dan $51,1 \%$ menjawab tidak. Hal ini penulis duga berpengaruh pada peningkatan prestasi kerja pegawai di PT. Armada Bandar Bangun Persada.

\section{LANDASAN TEORI}

\section{A. Teori Prestasi Kerja}

Menurut Mangkunegara (2002:67) prestasi kerja adalah "Hasil kerja secara kualitas dan kuantitas yang dicapai oleh seorang karyawan dalam melaksanakan tugasnya sesuai dengan tanggung jawab yang diberikan kepadanya". Menurut Handoko (2000:23), dalam mengungkapkan sebagai berikut: Prestasi kerja adalah suatu hasil kerja yang dicapai organisasi mengevaluasi atau menilai karyawannya. Dari pendapat diatas, dapat dijelaskan bahwa Keseluruhan unsur/komponen penilaian prestasi kerja diatas harus ada dalam pelaksanaan penilaian agar hasil penilaian dapat mencerminkan prestasi kerja dari para karyawan.

\section{B. Teori Insentif}

Insentif sebagai sarana yang mendorong para pegawai untuk bekerja dengan kemampuan yang optimal, yang dimaksudkan sebagai pendapatan ekstra di luar gaji atau upah yang telah ditentukan. Pemberian insentif dimaksudkan agar dapat memenuhi kebutuhan para pegawai dan keluarga mereka. Istilah sistem insentif pada umumnya digunakan untuk menggambarkan rencana-rencana pembayaran upah yang dikaitkan secara langsung atau tidak langsung dengan berbagai standar prestasi kerja PT. Armada Bandar Bangun Persada .

\section{Teori Pengawasan}

Pengawasan bisa didefinisikan sebagai suatu usaha sistematis oleh manajemen bisnis untuk membandingkan kinerja standar, rencana, atau tujuan yang telah ditentukan terlebih dahulu untuk menentukan apakah kinerja sejalan dengan standar tersebut dan untuk mengambil tindakan penyembuhan yang diperlukan untuk melihat bahwa sumber daya manusia digunakan dengan seefektif dan seefisien mungkin didalam mencapai tujuan.

Siagian, (2024:117) berpendapat bahwa evaluasi kerja atau penilaian dapat didefenisikan sebagai proses pengukuran dan pembandingan hasil-hasil pekerjaan yang nyatanya dicapai dengan hasil-hasil yang seharusnya dicapai.

Dale (dalam Winardi, 2000:224) dikatakan bahwa pengawasan tidak hanya melihat sesuatu dengan seksama dan melaporkan hasil kegiatan mengawasi, tetapi juga mengandung arti memperbaiki dan meluruskannya sehingga mencapai tujuan yang sesuai dengan apa yang direncanakan. Kesimpulannya, pengawasan merupakan suatu usaha sistematik untuk menetapkan standar pelaksanaan tujuan dengan tujuan-tujuan perencanaan, merancang system informasi umpan balik, membandingkan kegiatan nyata dengan standar yang telah ditetapkan 
sebelumnya, menentukan dan mengukur penyimpangan-penyimpangan serta mengambil tindakan koreksi yang diperlukan (Pandoyo, 2000:109).

\section{Teori Motivasi}

Motivasi didalam pribadi seseorang akan berpengaruh langsung terhadap tindakan yang akan dilakukannya, karena motivasi merupakan kekuatan yang ada dalam diri seseorang untuk berbuat sesuatu yang dapat memuaskan keinginannya. Setiap organisasi tentu ingin mencapai tujuannya.Untuk mencapai tujuan tersebut, peranan manusia yang terlibat di dalamnya sangat penting. Untuk menggerakan manusia agar sesuai dengan yang dikehendaki organisasi, maka haruslah dipahami motivasi yang menentukan prilaku orang-orang untuk bekerja, atau dengan kata lain prilaku merupakan cerminan yang paling sederhana dari motivasi

\section{E. Kerangka Konseptual}

Prestasikerja pegawai Di PT.Armada Bandar Bangun Persada diduga dipengaruhi oleh pemberian insentif ,motivasi dan pengawasan. Prestasi kerja merupakan suatu kegiatan yang dilakukan untuk melaksanakan, menyelesaikan tugas dan tanggung jawab sesuai dengan harapan dan tujuan yang telah ditetapkan. Pemberian insentif diduga dapat meningkatkan prestasi kerja pegawai dengan insentif yang diberikan akan memberikan minat bagi pegawai untuk dapat meningkatkan prestasi kerjanya

Motivasi merupakan mesin penggerak bagi individu maupun kelompok untuk dapat menjalankan aktivitasnya dengan sebaik mungkin agar tujuan organisasi dapat tercapai dengan baik. Dengan adanyan motivasi kerja yang baik dapat meningkatkan prestasi kerja pegawai. Pengawasan kerja juga diduga mempengaruhi prestasi kerja pegawai, karena dengan adanya pengawasan yang diadakan perusahan untuk menilai kinerja karyawan dan meningkatkan kualitas dan kuantitas kerja. Berdasarkan uraian diatas dapat digambarkan kerangka konseptual penelitian ini adalah sebagai berikut:

\section{F. Hipotesis Penelitian}

Hipotesis adalah jawaban sementara terhadap masalah yang kebenarannya harus di uji secara empiris. Berdasarkan permasalahan dan tujuan penelitian di atas maka dapat di ajukan hipotesis sebagai berikut :

1. Diduga terdapat pengaruh antara insentif terhadap prestasi kerja Pegawai PT.Armada Bandar Bangun Persada

$$
\begin{aligned}
\text { Ho : } & \beta_{1}=0 \\
\mathrm{Ha} & : \beta_{1} \neq 0
\end{aligned}
$$

2. Diduga terdapat pengaruh antara pengawasan terhadap prestasi kerja Pegawai PT.Armada Bandar Bangun Persada.

$$
\begin{array}{cc}
\text { Ho : } & \beta_{2}=0 \\
\text { Ha } & : \beta_{2} \neq 0
\end{array}
$$

3. Diduga terdapat pengaruh antara Motivasi kerja terhadap prestasi kerja Pegawai PT.Armada Bandar Bangun Persada. 


$$
\begin{gathered}
\text { Ho : } \beta_{3}=0 \\
\mathrm{Ha}: \beta_{3} \neq 0
\end{gathered}
$$

4. Diduga terdapat pengaruh secara bersama-sama antara insentif, pengawasan dan motivasi kerja terhadap prestasi kerja Pegawai PT.Armada Bandar Bangun Persada.

$$
\begin{array}{rc}
\text { Ho : } & \beta_{1}, \beta_{2}, \beta_{3}=0 \\
\text { На } & : \quad \beta_{1}, \beta_{2}, \beta_{3} \neq 0
\end{array}
$$

\section{METODOLOGI PENELITIAN}

Jenis penelitian ini tergolong pada penelitian Deskriptif dan Asosiatif (gambaran hubungan antar variabel). Menurut Siregar (2002: 15) menyatakan bahwa penelitian deskriptif asosiatif (gambaran hubungan antar variabel) adalah penelitian yang bertujuan untuk mengetahui hubungan sebab-akibat antara dua variabel atau lebih. Tempat penelitian ini dilaksanakan di kantor PT.Armada Bandar Bangun Persada waktu penelitian dilaksanakan bulan Juni 2016.

Populasi menurut Arikunto (2010:173) adalah keseluruhan subjek penelitian. Dalam penelitian ini yang menjadi populasi adalah Pegawai di kantor PT. Armada Bandar Bangun Persada. Populasi penelitian yang berjumlah 188 orang. Berdasarkan rumusan dari jumlah 118 orang pegawai yang dijadikan sampel sebanyak 93 orang. Sampel tersebut diambil dengan teknik "propotional random sampling" dengan menggunakan rumus:

Tabel 1: Kisi-kisi Instrumen Penelitian

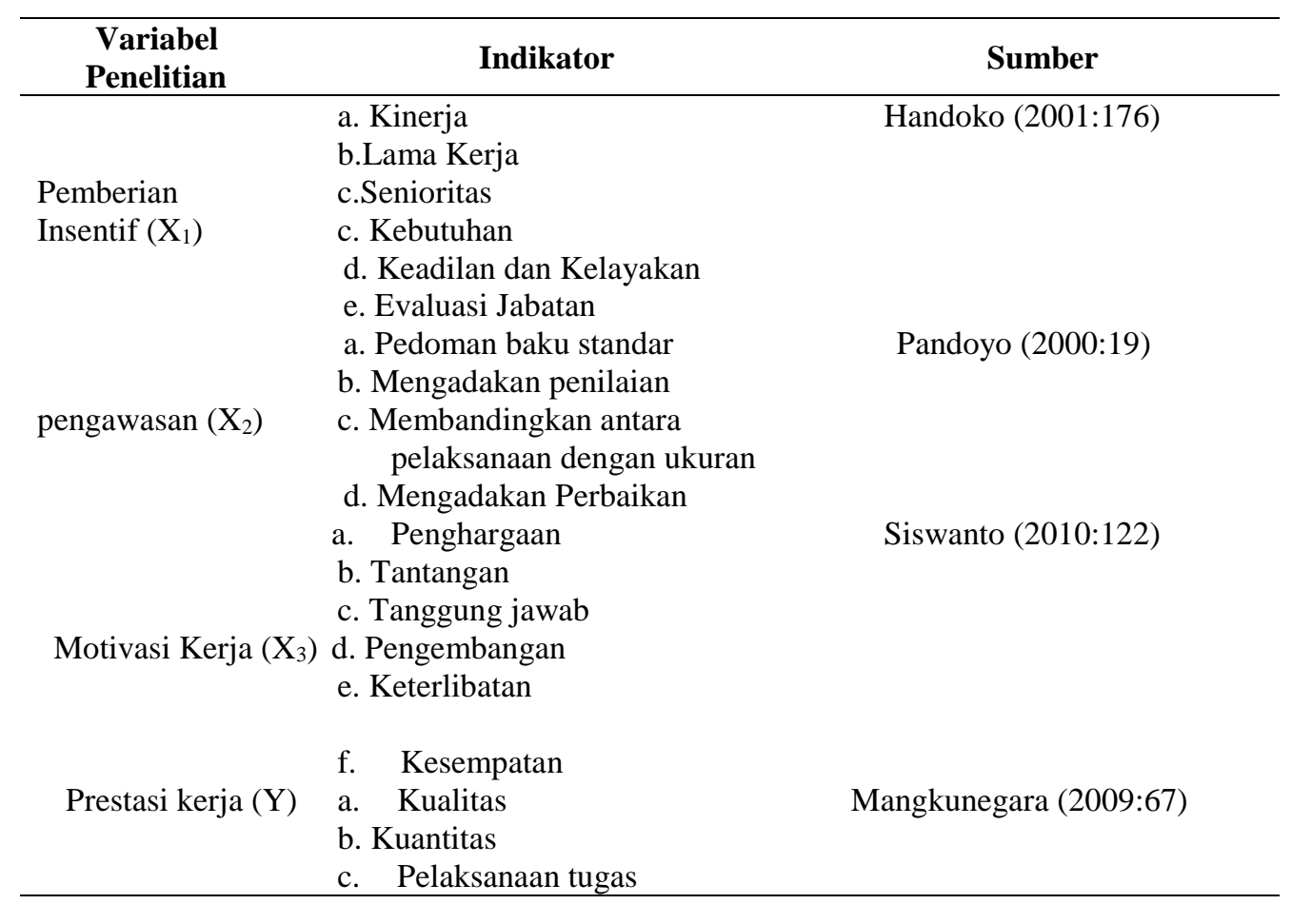

Majalah Ilmiah Bahari Jogja 108 | http://jurnal.amy.ac.id/index.php/MIBJ/ 
Uji coba instrumen ini akan dilaksanakan di kantor PT.Samudera Indonesia. Dari uji coba instrumen akan diperoleh butir-butir instrumen yang layak untuk dijadikan alat ukur. Layak atau tidaknya alat ukur tersebut dapat dilihat dari uji validitas dan uji reliabilitas

Tabel 2. Hasil Uji Validitas

\begin{tabular}{ccc}
\hline \multirow{2}{*}{ Variabel } & \multicolumn{2}{c}{ Keterangan } \\
\cline { 2 - 3 } & Valid & Tidak Valid \\
\hline Y & 9 & 1 \\
X1 & 12 & 6 \\
X2 & 9 & 3 \\
X3 & 14 & 4 \\
\hline
\end{tabular}

Tabel 3. Hasil Uji Reabilitas

\begin{tabular}{llll}
\hline \multicolumn{1}{c}{ Variabel } & Batas Nilai & Cronbach's Alpha & Keterangan \\
\hline Prestasi kerja & 0,600 & 0,874 & Reliable/handal \\
Pemberian insentif & 0,600 & 0,857 & Reliable/handal \\
Pengawasan & 0,600 & 0,824 & Reliable/handal \\
Motivasi kerja & 0,600 & 0,876 & Reliable/handal \\
\hline
\end{tabular}

\section{HASIL PENELITIAN DAN PEMBAHASAN}

\section{Tingkat Capaian Respodnen (TCR) Variabel X dan Y}

Hasil nilai TCR untuk variabel prestasi kerja pegawai adalah 84,97\% dengan kategori adalah baik. Artinya kinerja pegawai sudah baik. Hasil nilai TCR untuk variabel pemberian insentif adalah $73,27 \%$ dengan kategori adalah cukup baik. Artinya pemberian insentif yang diterapkan masih cukup baik. Variabel pengawasan dengan tingkat pencapaian $81,16 \%$ yang berada pada kategori baik. Artinya pengawasan yang dilakukan sudah baik. Nilai TCR motivasi kerja sebanyak 73,97\% berada pada kategori cukup baik. Artinya motivasi yang dimiliki pegawai masih berada pada kategori cukup baik.

\section{Koefisien Determinasi (R2)}

Berdasarkan hasil pada tabel 29 hasil pengolahan data yang dapat dilihat pada tabel diperoleh hasil nilai $\mathrm{R}$ square sebesar 0,351 yang artinya $35,1 \%$ perubahan pada variabel dependen (prestasi kerja) dapat dijelaskan oleh variabel independen (pemebrian insentif, pengawasan dan motivasi kerja) sedangkan sisanya sebesar $64,9 \%$ dipengaruhi oleh variabel lainyang tidak termasuk kedalam penelitian ini.

\section{Hasil Hipotesis}

\section{Hasil Uji t} adalah:

Pengaruh masing-masing variabel bebas yang mempengaruhi prestasi kerja

a. Hipotesis 1, terdapat pengaruh antara pemberian insentif (X1) terhadap prestasi kerja pegawai (Y).Diperoleh nilai koefisien regresi pemberian 
insentif sebesar 0,191dan nilai thitung sebesar 2,818>ttabel sebesar 1,986 sedangkan nilai signifikan $0,006<\alpha 0,05$, berarti Ha diterima dan $\mathrm{H} 0$ ditolak dengan demikian dapat dikatakan bahwa terdapat pengaruh antara pemberian insentif dengan prestasi kerja pegawai di PT.Armada Bandar Bangun Persada

b. Hipotesis 2, terdapat pengaruh antara pengawasan (X2) terhadap prestasi kerja pegawai (Y) Diperoleh nilai koefisien regresi pengawasan sebesar 0,283dan nilai thitung sebesar 3,269>ttabel sebesar 1,986 sedangkan nilai signifikan $0,002<\alpha 0,05$, berarti $\mathrm{Ha}$ diterima dan $\mathrm{H} 0$ ditolak dengan demikian dapat dikatakan bahwa terdapat pengaruh antara pengawasan dengan prestasi kerja pegawai di PT.Armada Bandar Bangun Persada .

c. Hipotesis 3,terdapat pengaruh antara motivasi kerja (X3) terhadap prestasi kerja pegawai (Y) Diperoleh nilai koefisien regresi pengawasan sebesar 0,135dan nilai thitung sebesar 2,332>ttabel sebesar 1,986 sedangkan nilai signifikan $0,022<\alpha 0,05$, berarti Ha diterima dan $\mathrm{H} 0$ ditolak dengan demikian dapat dikatakan bahwa terdapat pengaruh antara motivasi kerja dengan prestasi kerja pegawai PT. Armada Bandar Bangun Persada .

\section{Hasil Uji F}

Dari hasil pengolahan data dapat dilihat pada tabel 31di atas menunjukkan bahwa nilai Fhitung16,060> Ftabel3,10 dan nilai signifikan $0,000<0,05$. Hal ini berarti $\mathrm{HO}$ ditolak dan Ha diterima, Dengan demikian dapat dikatakan bahwa pemberian insentif, pengawasan dan motivasi kerja terhadap prestasi kerja pegawai di PT.Armada Bandar Bangun Persada.

\section{PENUTUP}

\section{Kesimpulan}

Berdasarkan hasil analisis data yang telah dilakukan dapat disimpulkan sebagai berikut:

1. Variabel pemberian insentif terdapat pengaruh antara pemberian insentif dengan prestasi kerja pegawai PT.Armada Bandar Bangun Persada.

2. Variabel pengawasan terdapat pengaruh antara pengawasan dengan prestasi kerja pegawai PT.Armada Bandar Bangun Persada.

3. Variabel motivasi terhadap prestasi kerja terdapat pengaruh antara motivasi kerja dengan prestasi kerja pegawai PT.Armada Bandar Bangun Persada.

4. Fhitung $16,060>$ Ftabel 3,10 dan nilai signifikan $0,000<0,05$. Hal ini berarti H0 ditolak dan Ha diterima, Dengan demikian dapat dikatakan bahwa pemberian insentif, pengawasan dan motivasi kerja terhadap prestasi kerja pegawai PT.Armada Bandar Bangun Persada.

\section{Saran}

1. Variable pemberian insentif dengan indikator terendah adalah lama kerja. disarankan kepada Pimpinan PT.Armada Bandar Bangun Persada agar lebih memperhatikan pemberian insentif berdasarkan lama kerja, karena pegawai yang sudah lama bekerja cenderung memiliki pengalaman yang banyak 
dibandingkan dengan pegawai yang baru dan juga mendapatkan insentif yang berbeda.

2. Variable pengawasan dengan indikator terendah adalah mengadakan penilaian. Disarankan kepada Pimpinan agar melakukan penilaian terhadap pengawasan yang telah dilakukan sehingga hasil dari penilaian tersebut bisa meningkatkan prestasi kerja pegawai.

3. Variable motivasi dengan indikator terendah adalah ketertiban. disarankan kepada pegawai untuk meningkatkan ketertiban dalam menjalankan tugas kepegawaian sehingga ketertiban tersebut bisa meningkatkan prestasi kerja pegawai.

\section{DAFTAR PUSTAKA}

Adila. (2011). Pengaruh Insentif Dan Motivasi Kerja Terhadap prestasi kerja Pegawai Pada Kantor Dinas Bina Marga Balai Besar Pelaksanaan Jalan Nasional III Satker Pelaksanaan Jalan Nasional Wilayah I Bandar Lampung. Jurnal, 1-14.

Admosudirdjo. (2005).Prinsip Pemasaran. Jakarta: bumi aksara.

Arikunto. (2010). Prosedur Penelitian Suatu pendekatan praktek. Jakarta: Renika Cipta.

Bungin. (2015). analisis Deskriptif. Bandung: bumi aksara.

Byrne, B. dan. (2008). Prosee3dur Penelitian Pendekatan Praktek. Jakarta:Renika Cipta.

Dessler, G. (2000). Sumberdaya Manusia. Jakarta: bumi aksara.

Ghozali, I. (2013). Aplikasi Analisis Multivarian Dengan Program IBM SPPS 21

Edisi 7. Semarang: Remaja Rosdakarya.

Handoko, H. (2000). Manajemen Sumberdaya Manusia. Jakarta: bumi aksara.

Huda, N. (2000). Pengaruh insentif Dan Motivasi Terhadap prestasi kerja

Karyawan Di Apotek Berkah Semarang. Jurnal, 1-15(maret).

Nengsih. (2015). Pengaruh insentif, pengawasan dan lingkungan kerja fisik testasi

kerja Pegawai Negeri Sipil Dinas Pendidikan Kota Padang. Jurnal, (November), 1-10.

Newman. (2002) Dasar- Dasar Ilmu Organisasi. Yogyakarta: PT. Raja Grafindo Persada.

Pandoyo. (2000). Panduan Riset Perilaku Konsumen. Semarang: PT. Granmedia

Pustaka Utama. Pangabean. (2002). Manajemen Pemasaran Dan Pemasaran Jasa. Bandung: Raja Grafindo Persada.

Rivai. (2014). Manejen Sumberdaya Manusia Untuk Perusahaan. Jakarta: Raja

Grafindo Persada

Robbins. (2007). Prilaku Organisasi. Jakarta: Salemba empat.

Sardiman, A. (2011). Manajemen Organisasi. Yogyakarta: PT. Granmedia

Pustaka Utama.

Siagian. (2002). Manajemen Sumber Daya Manusia. Jakarta: Ghalia Indonesia.

Siregar. (2002). Metode Penelitian Manajemen. Jakarta: bumi aksara. 
Siswanto. (2010).IManajemen Organisasi. Semarang: PT. Granmedia Pustaka Utama. Sugiyono. (2012). Metode Penelitian Bisnis. Bandung: Elfabeta.

Sukma. (2001). Prilaku Organisasi. Bandung: Salemba empat.

Suliyanto. (2002). D. prosedur penelitian. Jakarta: Renika Cipta.

Sutrisno. (2009). Prinsip- Prinsip Prilaku Organisasi. Semarang: PT. Raja Grafindo Persada.

Ukas. (2000). Panduan Riset Perilaku Konsumen. Surabaya: PT. Granmedia PustakaUtama.

Wahid, A. (2014). Pengaruh pengawasan, lingkungan kerja terhadap prestasi kerjakaryawan PT. Buana Jaya Yogyakarta. Jurnal, (November), 1-15.

Winardi. (2000). Prilaku Organisasi. Bandung: Salemba empat.

Winardi. (2001). Manajemen Personalia. Semarang: PT. Granmedia Pustaka Utama.

Wira. (2013). Pengaruh insentif dan motivasi terhadap prestasi kerja pegawai kelurahan dan Kecamatan Padang Timur Kota Padang. Jurnal, (maret), 1-15. Zuhad. (2002). Panduan Riset Perilaku Konsumen. Jakarta: bumi aksara 